\title{
Variations of Gerdy's tubercle, proposal of a morphological classification: Anatomical study and its clinical importance
}

\author{
SUNITA KALRA ${ }^{1 *}$, PUJA CHAUHAN ${ }^{2}$, ANKIT KHANDELWAL $^{3}$ \\ and POOJA RANI ${ }^{3}$
}

\author{
${ }^{1}$ Associate Professor, Department of Anatomy, University College of Medical Sciences, Delhi-110095, India \\ ${ }^{2}$ Associate Professor, Department of Anatomy, Shri Guru Ram Rai Institute of Medical and Health Sciences, \\ Dehradun, India \\ ${ }^{3}$ Senior Resident, Department of Anatomy, University College of Medical Sciences, Delhi-110095, India \\ ${ }^{*}$ E-mail: net3laug@yahoo.co.in
}

\begin{abstract}
Introduction: Gerdy's tubercle is described as a triangular facet in standard textbooks of human anatomy. The present study addresses the prevalence and shape of the anterolateral tubercle, which has been named as Gerdy's tubercle in adult human tibia. Examination of tibia revealed in excess of usual variations in the shape and texture of tubercle present at the anterior surface of lateral condyle of tibia. Material and Methods: The study was conducted on 103 ( 52 right and 51 left) of either sex dry Indian tibia bone to study the shape and texture of Gerdy's tubercle. The shape and texture of tubercle were very inconsistent and varied from a small circular smooth facet to very irregular rough facet. Results: Gerdy's tubercle was triangular \& smooth in $44.6 \%$, circular \& smooth in $17.4 \%$, vertically oval \& smooth in $2.9 \%$, transversely oval \& smooth in $3.8 \%$, irregular \& rough in $18.4 \%$ and triangular \& rough in $6.7 \%$. In $5.8 \%$ of tibia, it was unobtrusive. Conclusion: The different shapes of Gerdy's tubercle demonstrated in the present study may contribute to produce significant effect on surgical interventions and some shapes may be more prone to traumatic injuries on it.
\end{abstract}

Keywords: tibia, Gerdy’s tubercle, iliotibial tract, facet, fracture.

\section{Introduction}

Over the flattened lateral surface of the thigh, the fascia latae thickens to form a strong band, the iliotibial tract. The upper end of the tract splits into two layers, where it encloses and anchors tensor fasciae latae and receives, posteriorly, most of the tendon of gluteus maximus. The superficial layer ascends lateral to tensor fasciae latae to the iliac crest; the deeper layer passes up and medially, deep to the muscle, and blends with the lateral part of the capsule of the hip joint. Gray's anatomy describes that distally, the iliotibial tract is attached to a smooth, triangular, anterolateral facet on the lateral condyle of the tibia (Gerdy's tubercle) where it is superficial to and blends with an aponeurotic expansion from vastus lateralis (STANDRING, ELLIS, HEALY et al. 2005). It was named after French surgeon Pierre Nicolas Gerdy (1797-1856) (STANDRING, ELLIS, HEALY et al. 2005).

The term tubercle in Gerdy's tubercle is a misnomer. However, it is actually a facet present on upper end of tibia on the anterolateral surface of lateral condyle. Gray's anatomy describes it to be located around $1 \mathrm{~cm}$ below joint line and $2 \mathrm{~cm}$ lateral to tibial tuberosity and is produced by the tibial attachment of iliotibial tract (STANDRING, BORLEY, COLLINS et al., 2008). In the present study examination of tibia revealed more than usual variations in the shape and texture of tubercle present at the anterior surface of lateral condyle of tibia. The present study addresses the prevalence and shape of the anterolateral tubercle, which has been named as Gerdy's tubercle in adult human tibia. The term tubercle used here for the distal attachment of iliotibial tract is a misnomer. A tubercle is defined as a rounded projection on the surface of bone (WILLIAMS, BANNISTER, BERRY et al., 1995). Bones display articular surfaces at synovial joints with their neighbours, and if small, these are called facets. These osseous surfaces are smooth and are devoid of vascular foramina. In addition, some large tendons are attached to facets which lack regular contours of articular surfaces but resemble them in texture, being poorly vascularized and are sometimes depressed. In the current study, Gerdy's tubercle was found to be more of the facet than a tubercle.

\section{Materials and Methods}

The study was conducted on 103 dry Indian tibia bone of either sex (52 right and 51 left). Out of the 103 tibia examined 101 were adult and 2 tibia were of less than eighteen years of age - (epiphysial fusion not complete) of either sex available in the Department of Anatomy, University College of Medical Sciences.

The upper end of tibia was studied for presence, texture and shape of Gerdy's tubercle on the anterior surface of lateral condyle. The present study established that the term 'tubercle' in Gerdy's tubercle is a misnomer but actually it is a facet and was observed in 97 bones whereas was absent/ inconspicuous in 6 bones. The texture and shape was evaluated subjectively and facets classified into type Atriangular\& smooth, type B- circular \& smooth and, type C- vertically oval \&smooth, type D- transversely oval \& 
smooth, type E- Irregular \& rough and type F- triangular \& rough types.

\section{Results}

Of the 103 tibia examined 97 showed presence of Gerdy's tubercle and it was unobtrusive in 6 bones. The shape and texture of the tubercle was highly variable and was wide-ranging from a small circular smooth facet to entirely irregular rough facet. It was triangular \& smooth in $44.6 \%$, circular \& smooth in $17.4 \%$, vertically oval \& smooth in $2.9 \%$, transversely oval \& smooth in $3.8 \%$, irregular \& rough in $18.4 \%$ and triangular \& rough in $6.7 \%$. In $5.8 \%$ of tibia it was unobtrusive. Observations regarding variations of shape and texture are presented in Table 1 and in Figures 1-7.

\section{Discussion}

The present study has demonstrated in excess of usual variations in the shape and texture of Gerdy's tubercle. These variations have not been reported in the literature. Although different authors have described it to be of different shape but there is no consensus neither the shape of the Gerdy's tubercle nor any previous study has demonstrated its inconsistent shapes or texture. Atlas of Human anatomy has shown Gerdy's tubercle as transversely oval in one plate (NETTER, 2011) where as it has demonstrated it to be triangular in other plates (NETTER, 2011). Other studies (WILLIAMS, BANNISTER, BERRY et al., 1995) have described it as a flat but definite marking, which is triangular, and facet like on anterior aspect of lateral condyle of tibia but there was no statement of different shapes by them. Marking

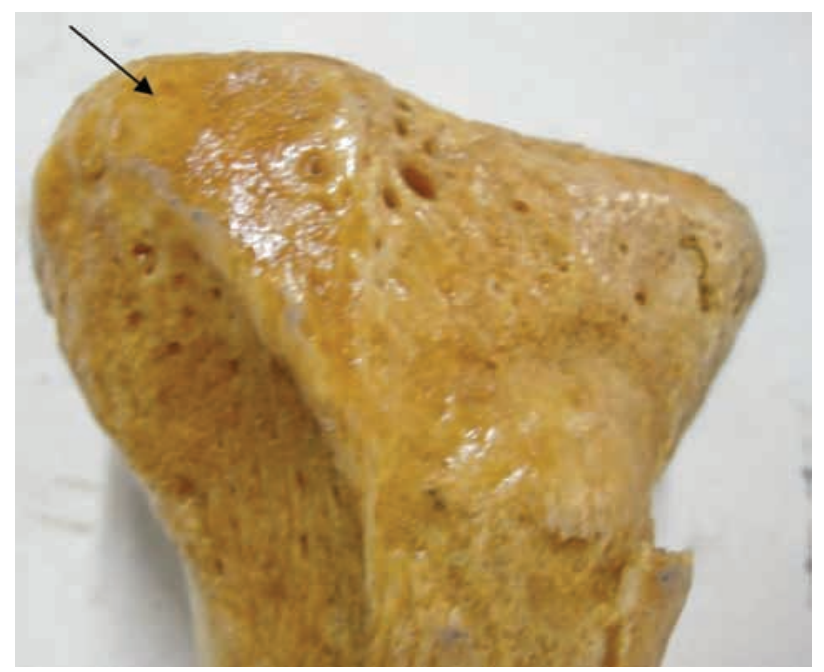

Figure 1. Triangular and smooth facet on right tibia- (Type A). on the figure shows epiphyseal line distal to it and capsular line proximal. Some other authors also labeled Gerdy's tubercle as irregular/triangular (AGUR and DALLEY, 2009; GILROY, MACPHERSON, ROSS et al., 2012).

It has been suggested (BENJAMIN, MORIGGL, BRENNER et al., 2004) that many tendons and ligaments advance towards their attachment sites obliquely, and as a consequence they often make contact with the bone immediately prior to their attachment in certain positions of the joint on which they act. This contact between tendon/ligament and bone influences stress dissipation at the enthesis itself. The attachment of a tendon/ ligament to the skeleton is obviously the fundamental function of any enthesis and vital to force transmission. Thus, tendons and ligaments often flare out at their attachment sites as an adaptation to securing skeletal anchorage and resisting the effects of insertional angle change. Flaring of enthesis is particularly striking in the limbs. Also, biomechanical studies (MAGANARIS, NARICI, ALMEKINDERS et al., 2004) illustrate that the strains within a tendon near its insertion site are in fact non-uniform. Even if the material properties are alike throughout the tendon, forces transferred through the insertion site may preferentially load the side of the tendon that is usually not principally affected. These areas of compressive loading correspond to the sites where tendinopathic characteristics are typically seen. These studies may possibly elucidate the highly variable shape and texture of Gerdy's tubercle found in the present study, which provides the attachment to ilioliotibial tract. We propose that as the muscles tensor fascia lata and gluteus maximus insert also into iliotibial tract, the differential pull over a

Table 1. Variations in the shape/texture of Gerdy's tubercle.

\begin{tabular}{lcccccccc}
\hline $\begin{array}{c}\text { Side/ } \\
\text { Shape \& } \\
\text { texture }\end{array}$ & $\begin{array}{c}\text { Triangular } \\
\text { Smooth } \\
\text { Type A }\end{array}$ & $\begin{array}{c}\text { Circular } \\
\text { Smooth } \\
\text { Type B }\end{array}$ & $\begin{array}{c}\text { Vertically } \\
\text { Oval } \\
\text { Smooth } \\
\text { Type C }\end{array}$ & $\begin{array}{c}\text { Transversely } \\
\text { oval } \\
\text { Smooth } \\
\text { Type D }\end{array}$ & $\begin{array}{c}\text { Irregular } \\
\text { Rough } \\
\text { Type E }\end{array}$ & $\begin{array}{c}\text { Triangular } \\
\text { \& rough } \\
\text { Type F }\end{array}$ & $\begin{array}{c}\text { Absent/ } \\
\text { unobtrusive }\end{array}$ & Total \\
\hline Right & 29 & 7 & 1 & 2 & 7 & 2 & 4 & 52 \\
Left & 17 & 11 & 2 & 2 & 12 & 5 & 2 & 51 \\
Total & 46 & 18 & 3 & 4 & 19 & 7 & 6 & 103 \\
& $(44.6 \%)$ & $(17.4 \%)$ & $(2.9 \%)$ & $(3.8 \%)$ & $(18.4 \%)$ & $(6.7 \%)$ & $(5.8 \%)$ & \\
\hline
\end{tabular}

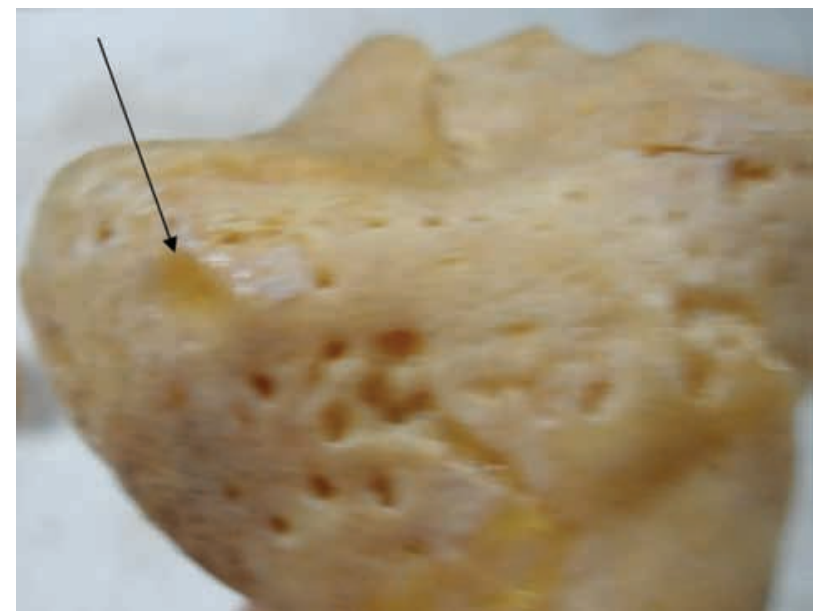

Figure 2. Circular and smooth facet on right tibia (Type B). 
long period provided by these muscles may be responsible for producing different shapes and texture of this.

The importance of Gerdy's tubercle in surgical practice is paramount. It is an important anatomical landmark for many surgical interventions in this region including bone graft or knee replacement surgeries. Another study

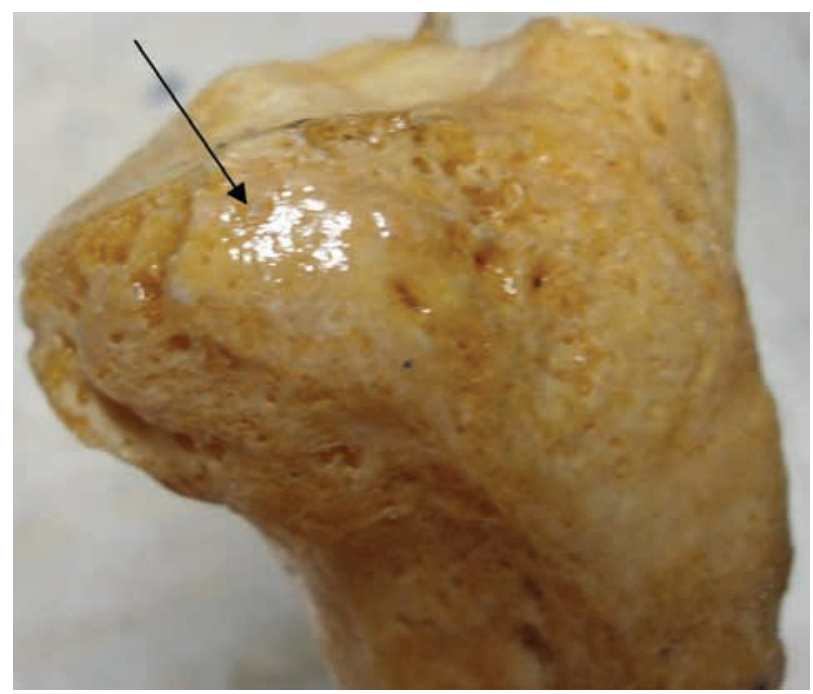

Figure 3. Vertically oval and smooth facet on right tibia (Type C).

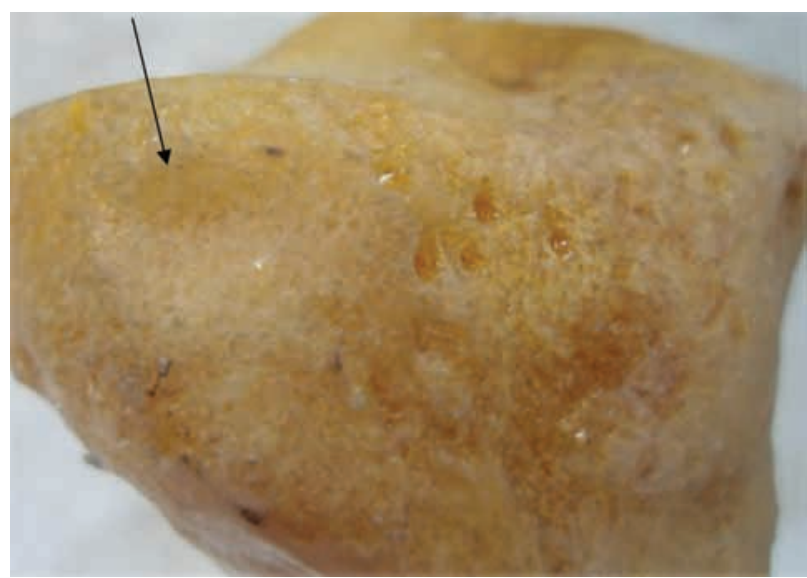

Figure 4. Transversely oval and smooth facet on right tibia (Type D).

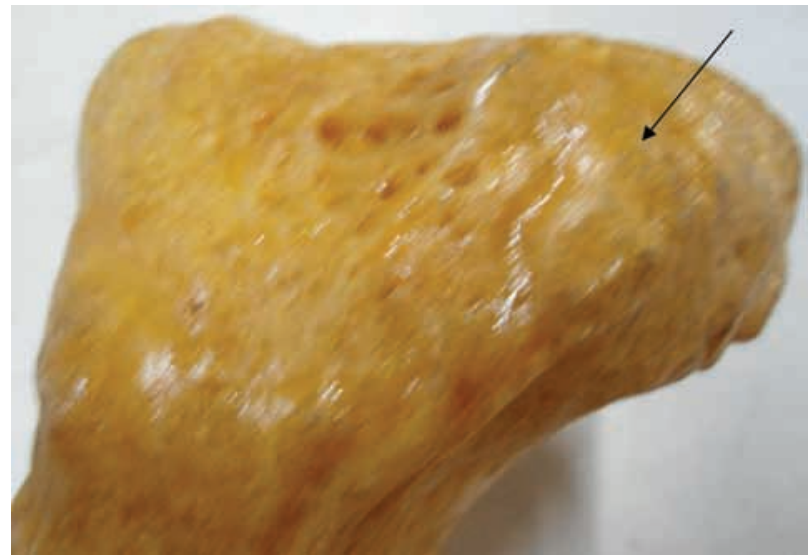

Figure 5. Irregular and rough tubercle on left tibia (Type E). demonstrated that the course of the common peroneal nerve and its proximal branch were noteworthy in two regards: their circular nature and their regular relationship to the most prominent portion of Gerdy's tubercle (RUBEL, SCHWARZBARD, LEONARD et al., 2004). With Gerdy's tubercle used as a signpost, the trajectory of the peroneal nerve was without doubt defined at the level of the proximal aspect of the tibia and marked previous to the placement of devices and instrumentation, thus avoiding injury to the peroneal nerve and its branches.

A case of en bloc avulsion fracture of tibial tuberosity and Gerdy's tubercle, has been reported (YOO, HAHN, YANG et al., 2007), in a fourteen year old patient. On CT scans, the fractured fragment was attached not only to patellar tendon but also to iliotibial band via Gerdy's tubercle. It was suggested that the injury was caused by the dynamic pull of quadriceps muscle via patellar tendon onto tibial tuberosity and the mostly static pull of ilio-tibial tract onto Gerdy's tubercle, both of which took a part in the fracture of the anterolateral portion of the unfused epiphysis of proximal tibia.

A new technique has been described which permits excellent visualization and fixation of lateral intra-articular coronal fractures of the femoral condyle (Hoffa fractures) based on osteotomy of Gerdy's tubercle and reflection of the attached iliotibial band (LIEBERGALL, WILBER, MOSHIEFF et al., 2000). These fractures are commonly treated surgically by open reduction and internal fixation.

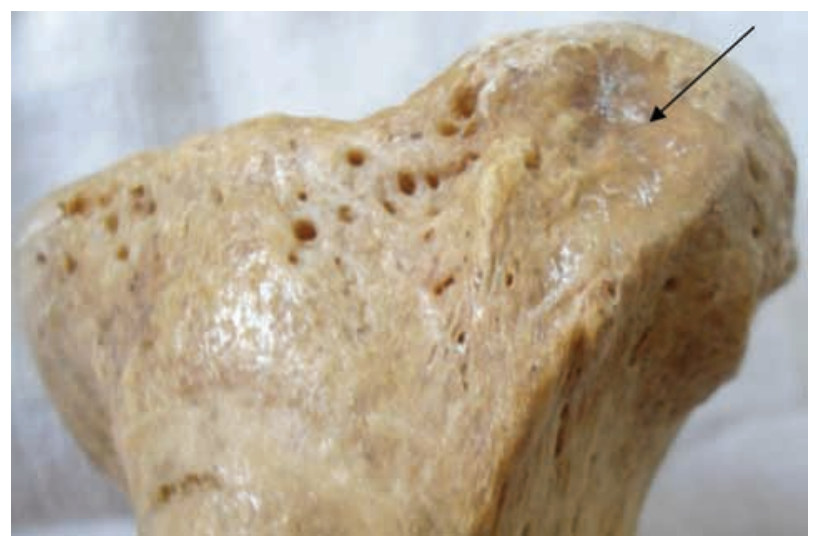

Figure 6. Triangular and rough facet on left tibia (Type F).

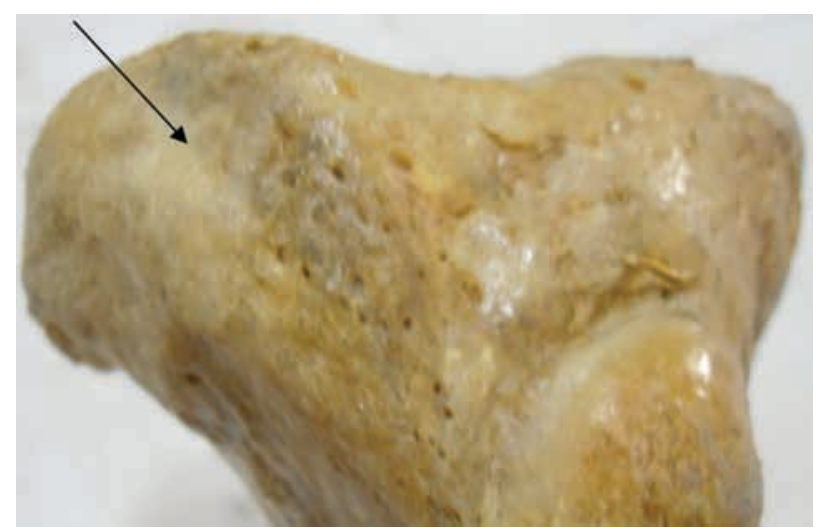

Figure 7. Unobtrusive facet on right tibia. 
Another study (BRUTUS and LOFTUS, 2006) suggested that cancellous bone grafts might be harvested from Gerdy's tubercle on the proximal metaphysis of the tibia for surgical procedures on the upper extremity. Proximal tibial bone harvesting is a recognized, important surgical procedure, harvesting bone for acute and chronic pathological defects. The lateral approach has been described using an oblique incision from Gerdy's tubercle to apex of tibial tuberosity to successfully allow entry through the cortex to harvest cancellous bone avoiding the epiphyseal line (BENNINGER, ROSSB and DELAMARTER, 2012).

\section{Conclusion}

The different shapes of Gerdy's tubercle demonstrated in the present study may contribute to produce significant effect on surgical interventions and may be some shapes are more prone to traumatic injuries on it. It is noteworthy that effects of these variations may initially remain silent but manifest abruptly with trauma or surgeries in the region. Apart from being of morphological interest these variations may be useful for clinical interest. Our study furnishes morphological information on Indian adult tibia bones, providing an anatomical baseline to correlate anatomical findings with surgical and radiological presentations. Further studies are required to assess the effects of its shape on various traumatic injuries and surgeries in this region.

\section{References}

AGUR, AMR. and DALLEY, AF. Grant's atlas of anatomy. 12th ed. Baltimore: Lippincott Williams \& Wilkins, 2009. p. 210.

BENJAMIN, M., MORIGGL, B., BRENNER, E., EMERY, P., MCGONAGLE, D. and REDMAN, S. The "enthesis organ" concept: why enthesopathies may not present as focal insertional disorders. Arthritis and Rheumatism, 2004, vol. 50, n. 10, p. 33063313. PMid:15476254. http://dx.doi.org/10.1002/art.20566

BENNINGER, B., ROSSB, A. and DELAMARTER, T. Approaches to proximal tibial bone harvest techniques. Journal of Oral o Maxillofacial Research, 2012, vol. 3, n. 2, p. e2. Available from: <http://www.ejomr.org/JOMR/archives/2012/2/e2/v3n2e2h. pdf>. PMid:24422009 PMCid:PMC3886101. http://dx.doi. org/10.5037/jomr.2012.3202

BRUTUS, JP. and LOFTUS, JB. Gerdy's tubercle as a source of cancellous bone graft for surgery of the upper extremity: description of technique. Journal of Hand Surgery, 2006, vol. 31, n. 1, p. 147-149. PMid:16443119. http://dx.doi.org/10.1016/j. jhsa.2005.07.011

GILROY, AM., MACPHERSON, BR., ROSS, LM., SCHUENKE, M., SCHULTE, E. and SCHUMACHER, U. Atlas of anatomy. 2nd ed. USA: Thieme, 2012. p. 404-406.

LIEBERGALL, M., WILBER, JH., MOSHIEFF, R. and SEGAL, D. Gerdy's tubercle osteotomy for the treatment of coronal fractures of the lateral femoral condyle. Journal of Orthopaedic Trauma, 2000, vol. 14, n. 3, p. 214-215. PMid:10791675. http://dx.doi. org/10.1097/00005131-200003000-00013

MAGANARIS, CN., NARICI, MV., ALMEKINDERS, LC. and MAFFULLI, N. Biomechanics and pathophysiology of overuse tendon injuries: ideas on insertional tendinopathy. Sports Medicine, 2004, vol. 34, n. 14, p. 1005-1017. PMid:15571430. http:// dx.doi.org/10.2165/00007256-200434140-00005

NETTER, FH. Atlas of human anatomy. 5th ed. Philadelphia: Saunders, 2011. p. 497; p. 501; p. 503.

RUBEL, IF., SCHWARZBARD, I., LEONARD, A. and CECE, D. Anatomic location of the peroneal nerve at the level of the proximal aspect of the tibia: Gerdy's safe zone. Journal of Bone and Joint Surgery, 2004, vol. 86-A, n. 8, p. 1625-1628. PMid:15292408.

STANDRING, S., ELLIS, H., HEALY, JC., JOHNSON, D., WILlIAMS, A., COLLINS, P. and WIGLEY, C. Gray's anatomy: the anatomical basis of clinical practice. 39th ed. New York: Elsevier Churchill Livingstone, 2005. p. 1419; p. 1553.

STANDRING, S., BORLEY, NR., COLLINS, P., CROSSMAN, AR. and GATZONLIS, MA. Gray's anatomy. 40th ed. London: Churchill Livingstone, 2008. p. 1340.

WILLIAMS, PL., BANNISTER, LH., BERRY, MM., COLLINS, P., DYSON, M., DUSSEK, JE. and FERGUSON, MWJ. Gray's anatomy. 38th ed. New York: Churchill Livingstone, 1995. p. 481483 ; p. 692-694.

YOO, JH., HAHN, SH., YANG, BK., YI, SR., AHN, YJ., YOON, DJ. and KIM, JH. An en bloc avulsion fracture of tibial tuberosity and Gerdy's tubercle in an adolescent basketball player: a case report. Knee Surgery, Sports Traumatology, Arthroscopy, 2007, vol. 15, n. 6, p. 781-785. PMid:17024477. http://dx.doi.org/10.1007/ s00167-006-0213-8 